\title{
Prescribing for geriatrics in Tehran; is it appropriate and rational?
}

\author{
Mona Kargar ${ }^{1}$, Fatemeh Atrianfar ${ }^{2}$, Arash Rashidian ${ }^{3}$, Kazem Heidari ${ }^{1}$, Maryam Noroozian ${ }^{4}$, \\ Kheirollah Gholami ${ }^{1}$, Mohammad Reza Javadi*1
}

Received: 15 Mar 2018

Published: 19 Dec 2019

\section{Abstract}

Background: The world's population is growing older. Inappropriate and irrational use of drugs in the elderly is a considerable health concern due to consequences such as increased morbidity and adverse drug events. This study aimed to evaluate the rationality of prescribing and determining the extent of inappropriate prescribing in a sample of geriatric patients in Tehran.

Methods: This cross sectional study was performed on 1512 prescriptions of patients aged $\geq 65$ years from 5 pharmacies affiliated to Tehran University of Medical Sciences in 2014. Prescription of potentially inappropriate medications (PIMs) was investigated using the Beers Criteria along with WHO prescribing indices. Date were analyzed using SPSS software, and significance level was set at less than 0.05 .

Results: Mean (SD) age of patients was 73.9(6.7) years. A total of $472(31.2 \%)$ patients received at least 1 PIM. Benzodiazepines were the most frequent drug class and general practitioners (GPs) were the most frequent prescriber of PIMs. The highest and the lowest percentage of prescriptions containing brand-names were prescribed by subspecialists $(62.5 \%)$ and GPs (42.2\%), respectively. Antibiotics and injectable medications were prescribed for $26.8 \%$ and $28.5 \%$ of patients by GPs. Mean (SD) number of drugs per prescription was 3.57 (1.92). Prescriptions containing systemic antibiotics and PIMs had significantly higher mean number of drugs compared to those without these items (both $\mathrm{P}<0.001$ ).

Conclusion: There is a need for interventions to improve the quality of prescribing for elderly patients, especially by GPs. Also, there are still some problems in rational use of drugs based on prescribing indices, especially, prescribing brand-names and injectable medications.

Keywords: Aged, Beers criteria, potentially inappropriate medication list, Inappropriate prescribing, Drug prescriptions, World Health Organization prescribing indices, Antibacterial agents, Injections

Conflicts of Interest: None declared

Funding: Tehran University of Medical Sciences \& health Services (Grant No. 92-02-156-23585)

\section{*This work has been published under CC BY-NC-SA 1.0 license.}

Copyright $\odot$ Iran University of Medical Sciences

Cite this article as: Kargar M, Atrianfar F, Rashidian A, Heidari K, Noroozian M, Gholami Kh, Javadi MR. Prescribing for geriatrics in Tehran; is it appropriate and rational? Med J Islam Repub Iran. 2019 (19 Dec);33:143. https://doi.org/10.47176/mjiri.33.143

\section{Introduction}

Older people often experience higher prevalence of chronic and multiple diseases that may lead to increased medication use (1). Moreover, prescribing for elderly is challenging due to altered pharmacokinetics, pharmaco-
Corresponding author: Dr Mohammad Reza Javadi, mrjavadi@sina.tums.ac.ir

1. Research Center for Rational Use of Drugs, Tehran University of Medical Sciences, Tehran, Iran

2. Faculty of Pharmacy, Tehran University of Medical Sciences, Tehran, Iran

3. Department of Health Management and Economics, School of Public Health, Tehran University of Medical Sciences, Tehran, Iran

4. Division of Memory and Behavioral Neurology, Department of Psychiatry, Roozbeh Hospital, Tehran University of Medical Sciences, Tehran, Iran $\uparrow$ What is "already known" in this topic:

Potentially inappropriate medications (PIMs) can predispose geriatrics to adverse drug events. Additionally, WHO prescribing indices can help to determine the rationality of administrations. Using the prescriptions, rather than the insurance claim data, can provide a more precise picture that can help to identify the prescribing problems and target the interventions more effectively.

\section{$\rightarrow$ What this article adds:}

Almost one-third of the patients received at least 1 PIM based on the Beers Criteria in Tehran, and general practitioners prescribed PIMs more frequently. On average, patients received 3.57 medications per prescription. Only $76.77 \%$ of all drugs were prescribed by generic names. Vitamins and corticosteroids were among the top injectable medications in this study. 
dynamics, and age-related changes in body composition and physiology (2). In previous studies, it has been shown that medication use increases with age in developed countries. It is not surprising that elderly are the highest group of drug consumers (3). Prescribing inappropriate medications for the elderly that result in wastage of health care resources due to adverse drug reactions (ADRs) is now a considerable concern (4). These medications can cause fall, fracture, delirium, and other preventable adverse drug events (5). In fact, it has been demonstrated that inappropriate prescribing can lead to mortality and morbidity along with the need for health care utilization in the elderly (6). Generally, inappropriate medications are defined as the medications that "pose more risk than benefit". Medications that are administered with either inappropriate dose/duration or drugs that can expose patients to considerable drug-drug or drug-disease interactions can also be included among the inappropriate medications (6). The importance of the detection of inappropriate prescribing is more pronounced considering the population aging. It is predicted that by 2020 the world will have 1 billion habitants older than 60 years of age, representing $22 \%$ of the global population (7). Iran is no exception (8), and it has been demonstrated that "the structure of the age pyramid has been reversed" in Iran in the last 2 decades (9).

Validated screening tools have been developed to identify potentially inappropriate medications (PIMs) in older adults. Among explicit prescribing indicators, the Beers Criteria is the most frequently cited tool to detect PIMs (4) and was first published in 1991 when used to assess medications of the residents of nursing homes (10). Then, it was expanded in 1997 to include "community-dwelling elderly" (11), revised in 2003 (12), and updated later (13). The 2012 version of the Beers Criteria divide inappropriate medications into 3 categories: (1) PIMs in older adults, (2) PIMs in older adults due to drug-disease or drugsyndrome interactions that may exacerbate the disease or syndrome, and (3) PIMs to be used with caution in older adults (13).

Another important issue in pharmacotherapy is the rational use of drugs. Based on the World Health Organization (WHO), use of drugs is considered rational when "patients receive medications appropriate to their clinical needs, in doses that meet their own individual requirements for an adequate period of time, and at the lowest cost to them and their community" (14). It was proposed that in developing countries, using WHO indicators for the evaluation of prescribing is important for promoting the rational use of drugs (14). The average number of drugs per prescription, the percentage of antibiotics, injectable drugs, drugs prescribed by generic name, and drugs prescribed from the essential drug list are among the prescribing indices developed by WHO (15). The average number of drugs per prescription was reported 1.3 to 2.2 in developed countries and 1.4 to 4.8 in developing countries in the general population (16). According to the WHO International Network of Rational Use of Drugs (INRUD), the optimal mean number of drugs per prescription is 3 or fewer. Additionally, the optimum percentage of prescriptions containing antibiotics and injectable drugs are up to
$30 \%$ and $10 \%$, respectively. Moreover, all of the drugs should be prescribed by generic name and within the essential drug list (17).

Considering the importance of assessing rational drug use and identifying the extent of inappropriate prescribing for geriatrics, which has not been widely documented in Iran, this study was conducted. In fact, having knowledge about the prevalence and quantifying the problem can help researchers to conduct interventional studies to improve medication therapy. Thus, the aim of the present study was to find the prevalence of prescribing PIMs using the Beers Criteria. Additionally, we intended to assess the rationality of prescribing using the WHO prescribing indices in a sample of geriatric prescriptions.

\section{Methods}

\section{Study design}

This retrospective cross sectional study, conducted from January to March 2014, was part of a project that evaluated different aspects of pharmacotherapy for outpatient geriatrics $(18,19)$. Data of 1512 insurance prescriptions of patients aged $\geq 65$ years were collected from 5 pharmacies (Amini, Booali, Isar, Taleghani and Abedini) affiliated to the Faculty of Pharmacy, Tehran University of Medical Sciences (TUMS). The study was approved by the ethic committee of TUMS.

At the time of the study, there were 4 main insurance organizations that paid medical expenses of the majority of the population in Iran. Number of prescriptions from insurance organizations was determined based on the proportion of the population under their coverage. The data of prescriptions, including the specialty of the prescriber, number, dosage form, dose of each medicine, and the demographics of patients were entered into Excel (Microsoft office). Physicians were categorized based on both their specialty and their level of education. To compare different medical specialty branches, all specialists and subspecialists of the same branch were assessed together.

\section{Investigation of PIMs}

The 2012 version of the Beers Criteria was applied to identify PIMs prescribed for older adults (13). Inappropriate medications that should generally be avoided regardless of the drug-disease or drug-syndrome interactions were evaluated in this study. Selection of this category was due to the unavailability of medical records of patients in pharmacies. However, in the selected list, which included 34 medications or medication classes, there were still items that needed some modifications. The medications of the mentioned category were divided into 2 groups: the first group "the generally inappropriate medications (GIM)" consisted of the items that the criteria recommended to be avoided or the researcher could determine their appropriateness based on the criteria using the prescription data; the second group included medications whose appropriateness could be judged only based on additional data.

In fact, based on the selected list of the criteria, several drugs should be considered inappropriate if they are prescribed exceeding a certain dose (eg, doxepin $>6 \mathrm{mg} / \mathrm{d}$ 
and digoxin $>0.125 \mathrm{mg} / \mathrm{d}$ ) or duration (eg, zolpidem $>90$ days, nitrofurantoin for long-term suppression). For some medications, prescribing for special indications are deemed to be inappropriate: i.e. $\alpha_{1}$ blockers for hypertension; antipsychotics for behavioral problems of dementia unless non-pharmacological options have failed and the patient is a threat to self or others; clonidine as a first-line antihypertensive, and benzodiazepines for the treatment of insomnia, agitation, or delirium. Moreover, in some cases, medications are considered inappropriate if they are prescribed for patients with special medical conditions such as nitrofurantoin in creatinine clearance $<60 \mathrm{~mL} / \mathrm{min}$.

Among the above-mentioned cases, whenever the appropriateness could be judged based on the prescription data, the medications were categorized in the GIM group. The complete list of the modified Beers Criteria is available in Supplementary Table 1. Whenever the data that could help to clarify the appropriateness of the medications were not provided in the prescriptions, the medications were considered to be conditionally inappropriate medications (CIMs). Moreover, the total number of PIMs was calculated by summing up the number of encounters with GIM and CIM.

\section{Prescribing indices}

The core drug use indicators of the WHO were used (15): percentage of medicines prescribed by generic name, number of drugs per prescription, and percentage of encounters with injectable drugs and antibiotics.

Antibiotics were selected based on the WHO model list presented by INRUD (20). To have a more comprehensive list, several antibiotics were added from the essential drug list of the WHO. For example, since ciprofloxacin is included in the WHO model list, levofloxacin the same class agent, was added as well. Other drugs that were added due to their similarities were nalidixic acid, ofloxacin, gemifloxacin, moxifloxacin, tetracycline, amikacin, streptomycin, tobramycin, and gentamicin. Additionally, several cephalosporins (cefuroxime, ceftizoxime, and cefepime) and penicillins (benzathine salt of phenoxymethyl penicillin), along with ampicillin/sulbactam, piperacillin/tazobactam and meropenem, were added to the list. Moreover, different strength of the included dosage forms of the medications were included. The ophthalmic dosage form of ofloxacin, ciprofloxacin, and erythromycin were also included in the antibiotic list since their systemic dosage forms were already in the list. The complete list of the antibiotics that was used in the present study is available in Supplementary Table 2.

To evaluate the extent of generic-name prescribing, medication names listed in Iran Drug List were considered as generic names. Others, including the name of herbal medicines and branded generics, were considered as brands.

Polypharmacy was defined as the presence of 5 or more drugs per prescription. Moreover, due to the tendency of the elderly patients to use herbal medicines, this category of drugs was reported separately.

\section{Statistical analysis}

Descriptive statistics were reported using mean (SD) for quantitative variables and frequency (percentage) for the qualitative. The mean number of inappropriate medications and the number of prescribed drugs within different prescribers' educational levels and specialties were compared using Kruskal-Wallis test. Number of drugs prescribed as CIM, GIM, and PIM per prescription were also compared by Kruskal-Wallis test. In addition, the comparison between the number of inappropriate medications and the number of prescribed drugs was performed using the Spearman's correlation. Date were analyzed using the SPSS software, and significance level was set at less than 0.05 .

\section{Results}

A total of 1512 prescriptions containing 5450 drugs, which were obtained from 5 pharmacies affiliated to TUMS, were evaluated in this study. The mean (SD) age of the patients was 73.9(6.7) years, and $790(52.4 \%)$ patients were male. General practitioners (GPs), by 474 (31.3\%) prescriptions, were the largest group of prescribers followed by internists and cardiologists among the specialists (357 and 214 prescriptions, respectively).

\section{PIM}

At least 1 GIM and CIM was detected in 399 (26.4\%) and $125(8.3 \%)$, prescriptions respectively. From 5450 medications in the prescriptions, 481 (8.25\%) and 132 (2.4\%) drugs were among the GIMs and CIMs, respectively. In fact, in $472(31.2 \%)$ prescriptions, at least 1 PIM was encountered, which consisted of 613 (11.24\%) medications (Table 1).

The mean (SD) number of GIMs, CIMs, and PIMs per prescription was $0.32(0.57), 0.09$ (0.29), and 0.40 (0.67), respectively. The most frequent GIMs were chlorpheniramine $(n=86,17.9 \%)$, glibenclamide $(n=66,13.72 \%)$, alprazolam $(n=55,11.4 \%)$, chlordiazepoxide $(n=29,6 \%)$, clonazepam $(n=26,5.4 \%)$, clidinium-c $(n=25,5.2 \%)$, and prazosin $(n=21,0.43 \%)$. Among the CIMs, diphenhydramine $(n=40,30.3 \%)$ was the most frequently prescribed medication (Tables 2 and 3). Benzodiazepines ( $n=153)$ and anticholinergics $(n=140)$ were the most frequently

\begin{tabular}{|c|c|c|c|c|c|}
\hline \multirow[t]{3}{*}{ Categories of Inappropriate Medications } & \multicolumn{5}{|c|}{ Number of Inappropriate Medications in Prescriptions } \\
\hline & 0 & 1 & 2 & 3 & 4 \\
\hline & $\mathrm{N}(\%)$ & $\mathrm{N}(\%)$ & $\mathrm{N}(\%)$ & $\mathrm{N}(\%)$ & $\mathrm{N}(\%)$ \\
\hline CIM & $1387(91.7)$ & $118(7.8)$ & $7(0.5)$ & 0 & 0 \\
\hline GIM & $1113(73.6)$ & $321(21.2)$ & $74(4.9)$ & $4(0.3)$ & 0 \\
\hline PIM & $1040(68.8)$ & $349(23.1)$ & $107(7.1)$ & $14(0.9)$ & $2(0.1)$ \\
\hline
\end{tabular}


Table 2. Frequency of prescribed conditionally inappropriate medications (drugs/drug class)

\begin{tabular}{lcc}
\hline & CIM drugs or drug class & $\mathrm{n}$ \\
\hline 1 & Antipsychotics & 45 \\
2 & Anticholinergics & 40 \\
3 & Spironolactones & 19 \\
4 & Antiarrhythmics & 10 \\
5 & Metoclopramide & 9 \\
6 & Estrogens & 5 \\
7 & Digoxin & 4 \\
& Total & 132 \\
\hline
\end{tabular}

CIM: Conditionally Inappropriate Medications

Table 3. Frequency of prescribed generally inappropriate medications (drugs/drug class)

\begin{tabular}{ccc}
\hline & GIM drugs or drug class & $\mathrm{n}$ \\
\hline 1 & Benzodiazepines & 153 \\
2 & Anticholinergics & 100 \\
3 & Sulfonuurea, Antidiabetics & 66 \\
4 & Antispasmodics & 43 \\
5 & Alpha Blockers & 25 \\
6 & Tricyclic Antidepressants & 21 \\
7 & Muscle Relaxants & 16 \\
8 & Antithrombotics & 12 \\
9 & Indomethacin & 12 \\
10 & Non-Steroidal Anti-Inflammatory Drugs & 9 \\
11 & Ketorolac & 7 \\
12 & Antiparkinson agents & 5 \\
13 & Digoxin & 3 \\
14 & Thioridazine & 3 \\
15 & Barbiturates & 2 \\
16 & Nifedipine & 2 \\
17 & Estrogen & 1 \\
18 & Non-Benzodiazepine Hypnotics & 1 \\
& Total & 481 \\
\hline
\end{tabular}

GIM: Generally Inappropriate Medications

prescribed medication classes considered inappropriate in this survey.

GPs were responsible for the highest proportion of potentially inappropriate prescribing compared to other prescribers' groups. We found at least 1 PIM in 228 prescriptions by GPs $(48.1 \%)$. Among specialists with $>50$ prescriptions, PIMs were more frequently prescribed by neurologists (26 prescriptions, 38.8\%). Cardiologists (54 prescriptions, $25.2 \%$ ) and internists (90 prescriptions, 25.2\%) were the following groups of specialists with similarly high frequency of prescribing inappropriate medications. Additionally, it was found that the differences between the mean numbers of inappropriate medications per prescription were statistically significant among prescribers with various educational levels (Table 4). This significant difference was also found in multiple comparisons.

The results of this study showed that the mean number of drugs in prescriptions with at least 1 CIM, GIM, and PIM were significantly higher than the prescriptions that did not contain them ( 4.4 vs $3.5,4.5$ vs 3.2 , and 4.4 vs 3.1 for prescriptions with and without CIM, GIM, and PIM, respectively $\mathrm{p}<0.001$ in all cases).

\section{Prescribing indices}

The mean (SD) number of drugs per prescription was 3.57 (1.92) and ranged from 1 to 10 . Prevalence of polypharmacy in the prescriptions by GPs, internists, and cardiologists was $14.5 \%, 19.3 \%$, and $29.9 \%$, respectively. Totally, polypharmacy was detected in $29.9 \%$ of prescriptions. Moreover, the mean number of medicines per prescription was higher in women's prescriptions (3.7) vs men's (3.4) $(\mathrm{p}<0.001)$.

Among the total medications, $1266(23.22 \%)$ prescribed items were brand-name drugs. The highest and lowest percentage of prescriptions with at least 1 brand-name drug was prescribed by subspecialists $(62.5 \%)$ and GPs (42.2\%), respectively. Cardiologists $(76.6 \%)$, neurologists (70.1\%), and orthopedists $(62.7 \%)$ had the higher percentages of prescriptions with at least 1 of brand-name medication among the specialists, respectively.

This study showed that $352(23.3 \%)$ prescriptions included at least 1 injectable drug. Orthopedists (54.9\%), GPs $(28.5 \%)$, and internists $(24.6 \%)$ were the first 3 groups with higher percentage of injectable drugs in the prescriptions, respectively.

Overall, $271(18.0 \%)$ prescriptions included at least 1 antibiotic. The mean (SD) number of antibiotics was 0.22 $(0.52)$ per prescription and consisted of $0.21(0.50)$ systemic, and $0.01(0.11)$ topical agents. GPs (26.8\%), ophthalmologists $(15.4 \%)$, and internists $(14 \%)$ had higher percentages of antibiotics in their prescriptions. It was also found that $52.6 \%$ of local antibiotics were prescribed by ophthalmologists. Prescriptions with at least 1 systemic antibiotic had significantly higher mean number of drugs per prescription compared to prescriptions without these medications (3.9 vs 3.1 respectively, $\mathrm{p}<0.001$ ).

Herbal drugs were prescribed for $73(4.8 \%)$ patients. Orthopedists were the most frequent prescribers of herbal medicines ( $11.8 \%$ of their prescriptions). The most frequent injectable drugs, herbal medicines, local and systemic antibiotics, and brand-name drugs are summarized in Table 5.

\section{Prescribing indices in the prescriptions by GPS}

The mean (SD) number of drugs in prescriptions was 3.63 (1.8), and the mean (SD) number of brand-name drugs in these prescriptions was $0.56(0.8)$ which consisted of 267 items (15.49\%). In the prescriptions of GPs, 127

Table 4. Mean number of potentially inappropriate medications in the prescriptions of prescribers with different level of education

\begin{tabular}{lccc}
\hline Specialty & $\begin{array}{c}\text { Mean number of CIM } \\
(\text { SD } ¥\end{array}$ & $\begin{array}{c}\text { Mean number of GIM } \\
(\text { SD })\end{array}$ & $\begin{array}{c}\text { Mean number of PIM } \\
(\text { SD) }\end{array}$ \\
\hline General practitioner $(\mathrm{n}=474)$ & $0.1(0.32)$ & $0.54(0.69)$ & $0.64(0.77)$ \\
Resident $(\mathrm{n}=115)$ & $0.09(0.32)$ & $0.13(0.42)$ & $0.22(0.57)$ \\
Specialist $(\mathrm{n}=620)$ & $0.09(0.30)$ & $0.25(0.51)$ & $0.34(0.64)$ \\
Subspecialist $(\mathrm{n}=296) \dagger$ & $0.04(0.21)$ & $0.19(0.39)$ & $0.23(0.46)$ \\
P value + & 0.015 & $<0.001$ & $<0.001$ \\
\hline
\end{tabular}

$¥$ Mean numbers are reported per prescription

† The remaining 7 prescriptions were written by dentists

† Kruskal Wallis Test

CIM: Conditionally Inappropriate Medications, GIM: Generally Inappropriate Medications, PIM: Potentially Inappropriate Medications 
Table 5. The most frequently prescribed injectable drugs, herbal drugs, antibiotics, and brand-name drugs in 1512 prescriptions

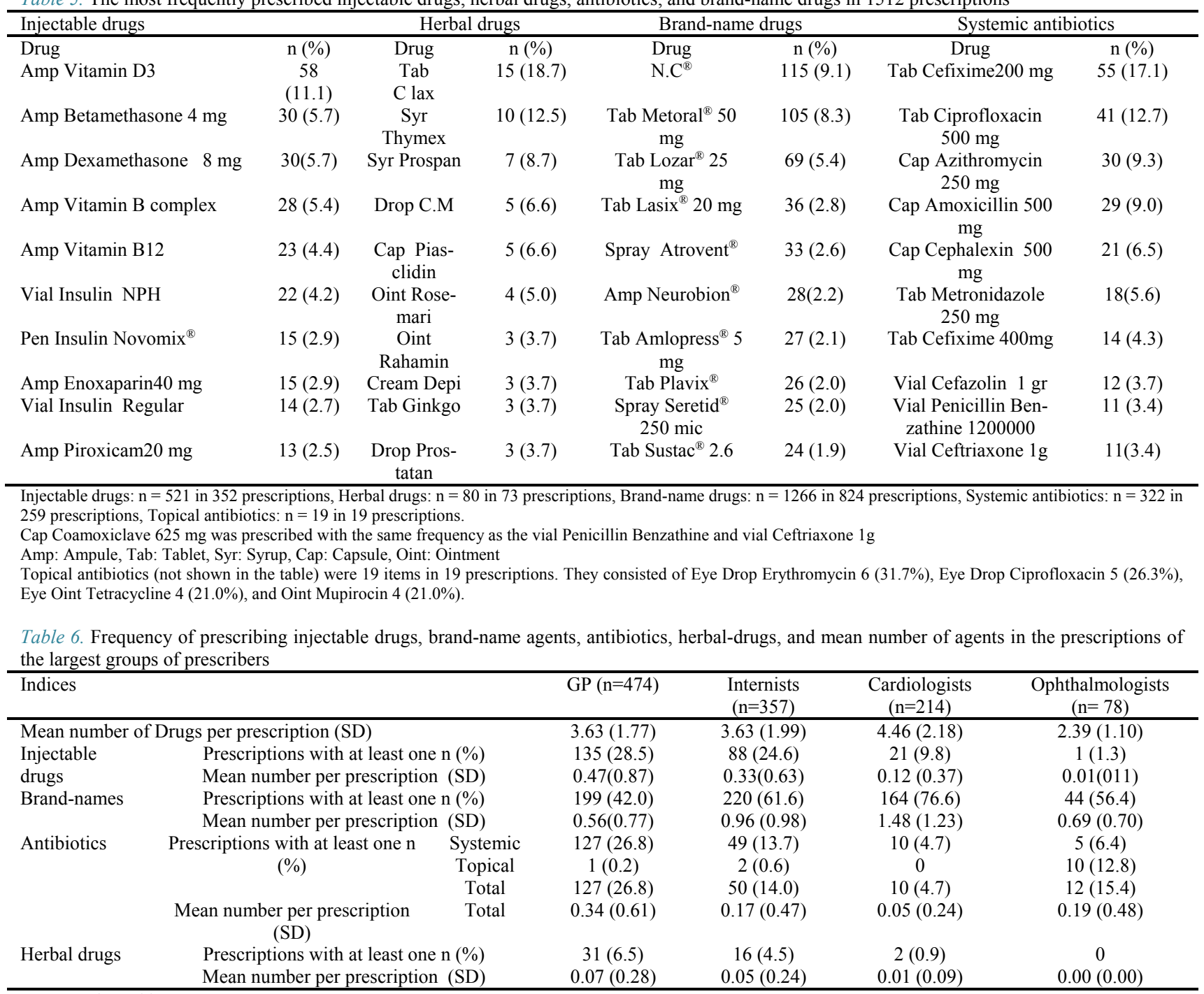

GP: general practitioners

$(26.8 \%)$ and $135(28.5 \%)$ prescriptions contained at least 1 systemic antibiotic and injectable drugs, respectively (Table 6).

\section{Discussion}

In the present study, the prescribing indicators and inappropriate medications were investigated in a sample of geriatric prescriptions. We found that $31.2 \%$ of the patients were exposed to at least 1 PIM. This consisted of both CIMs and GIMs, which were observed in $8.3 \%$ and $26.4 \%$ of the prescriptions, respectively. The frequency of PIMs in this study was similar to the previous studies in Iran that reported the frequency of $20 \%-30 \%$ based on the Beers Criteria. However, the studies were conducted using either the 2003 or 1997 version of the criteria (21-24). To the best of the authors' knowledge, the only study that was performed with the 2012 version of the criteria in Iran was the study by Talebi-Taher et al on hospitalized geriatric patients (25). They reported the frequency of PIMs to be $22.3 \%$. Due to the availability of patients' charts in the hospital, it was assumed that the researchers could have detected drug-disease interactions. However, the study method was vague and data were not presented clearly.

Benzodiazepines were the most frequently prescribed inappropriate class of medications in this study, which is consistent with several other reports that showed benzodiazepines among the top frequently prescribed inappropriate drug classes $(22,23,25)$. Studies from Turkey, Lebanon (21), Irland (26) and Japan (27) reported the prevalence of PIMs to be $9.8 \%, 22 \%, 25 \%$, and $43.6 \%$ according to the previous versions of the Beers Criteria, respectively. PIM prescribing based on the 2012 updated criteria was documented in some studies in different countries and ranged from $16 \%$ among Indian inpatients (28) to $59.2 \%$ in Brazilian aged population (29). Similar studies in Nigeria (30), India (31), and New Zealand (32) reported the frequency of PIMs to be $25.5 \%, 21.8 \%$, and $42.7 \%$, respectively. The diversity in the prevalence of PIMs reported in various studies can be to some extent attributed to the difference in the availability of inappropriate medications in the countries, differences in patients (31), and the accessibility of medical charts in the study 
settings. In addition, whether the practitioners included only GPs or the specialists, could also make a difference. Moreover, evaluating a single prescription or all the medications used by patients may lead to different results. For example, in a study by Baldoni et al, not only the current medications of the patient but also the medication used within the preceding month were evaluated (29). In one study in Japan, all the prescriptions of patients during the study period were evaluated and only those patients with at least 2 pharmacy claims during the study period were included (27). The considerable point is that both studies reported a high prevalence of PIM.

The most common GIMs prescribed in the present study were chlorpheniramine, glibenclamide, alprazolam, and chlordiazepoxide. Similarly, antihistamines in Nigeria (30) and both chlorpheniramine and alprazolam in India (31) were among the prevalent prescribed PIMs. The recently reported prevalence of PIMs in a large American survey was $30.9 \%$ using the qualified definition of the 2012 Beers Criteria (33). With an acceptable agreement with the method of the present study, the study by Davidoff et al generated 2 definitions for PIMs using the Beers 2012 Criteria based on the specific restrictions related to dose, route, duration, and medical conditions. The "broad definition" in which special route and dose of drugs were considered inappropriate in the elderly was almost comparable to the GIMs in the present study. In the same way, the "qualified definition" in their study was similar to the CIMs in this study, considering more restrictions such as duration and medical conditions. The main difference between the 2 studies was the unavailability of patients' diagnosis, coexisting diseases, and medical conditions in the present study. Among the 5 most frequently prescribed categories of PIMs, benzodiazepines, first generation antihistamines, and sulfonylureas were similar inappropriate medications in the present study as well as in the study by Davidoff et al (33).

The evaluation of rational prescribing based on the WHO prescribing indices has been previously performed in several studies $(16,34-37)$. WHO indicators were not primarily developed for the elderly; rather, they are assessment tools for GPs' prescribing practice, irrespective of patients' age.

The average number of drugs per prescription in this study was 3.57 , which is higher than 3.07 reported by Karimi et al in a study on the prescriptions of GPs as well as the specialists in all age groups (35). In 2 studies that evaluated the prescriptions of health centers, the average number of drugs per prescription was 3.03 (16) and 3.4 (37).

It seems that the higher need for medications by geriatrics may be presented with a higher mean number of drugs per prescription. However, in this study, this number was lower compared to 3.8 (30) and 3.9 (38) reported from studies on elderly outpatients of 2 Nigerian hospitals and 4.27 in prescriptions of elderly outpatients of a tertiary hospital clinic in India (39). However, the health care system is important in the interpretation of the results. For example, Eze et al. noted that high mean number of medications per prescription was also reported in previous studies in Nigeria (38).

Similar to the present study, a Swedish study found a higher number of drugs being prescribed for the elderly women compared to men. However, Craftman et al documented all medications used by the elderly in their study and not a single prescription (40). Considering the prescriptions by GPs, the mean number of drugs per patient in this study was 3.63 , which was lower compared to the study by Ghadimi et al, in which they reported 4.4 items per prescription in the GPs' prescriptions for the elderly (21). However, as it was expected, both numbers are higher than the reported mean number of items by Safaeian et al (3.3) in a study that included the prescriptions of all age groups (41).

The results showed that the percentage of drugs prescribed by generic names was $76.77 \%$ and $84.51 \%$ among the prescription of all prescribers and GPs, respectively. The mentioned percentages were lower compared to previous Iranian studies that reported more than $95 \%$ of drug encounters were by generic names $(16,21)$. The difference with other Iranian studies can be attributed to the method of assessment. In fact, one of the advantages of the present study, compared to the previous studies in Iran $(21,35)$, was documenting the entire prescription items, not only evaluating the insurance claims data. Using the insurance data has several limitations: the uncovered items by the insurance organizations cannot be included in the data. Thus, supplements and herbal medications are underreported. Moreover, only items that were purchased by the patient (not all of the prescribed items by the physicians) can be reported. Therefore, the number of drugs per prescription was more accurate in the data of this study. Moreover, most of the times, the branded-generic names are entered in the insurance claims by their generic name in Iran. Therefore, the data by the insurance organizations generally underreport the brand-name prescribing.

The brand-name prescribing in this study was less than half of the reports from the studies in other countries like Nigeria $(30,38)$ and was nearly comparable to the reports from Brazil (42). To the best of the authors' knowledge, the previous studies in Iran have not evaluated the brandname prescribing among different specialties or educational levels of prescribers. Antibiotics were prescribed by GPs in $26.8 \%$ of their prescriptions, which was much lower than the figures for both the elderly (39\%) (21) and the general population $(51 \%)$ of the country $(35,41)$. Also, the frequency of antibiotic prescription in this study was within the standard range recommended by the WHO (not higher than 30\%) (35). Similarly, the percentage of the injectable drugs in the GPs' prescriptions (28.5\%) was lower compared to other studies $(21,41)$. However, vitamins and corticosteroids were among the top injectable medications in this study, which deserve consideration.

Comparable to the previous studies $(35,36)$, the average number of medicines per patient differed based on the physicians' specialty. In other studies, similar to the results of this study, ophthalmologists were among the prescribers with the least number of medications in their prescriptions $(35,36)$.

Among the prescribers, GPs and ophthalmologists pre- 
scribed higher percentage of antibiotics in prescriptions in the present study, while antibiotics were mostly prescribed by GPs, ENT specialists $(35,36)$, and general surgeons (36) in other studies. Orthopedists and GPs were the first and the second highly prescribers of injections both in the present study and the study by Sadeghian et al (36).

\section{Limitations}

The main limitation of the present study was the unavailability of medical records of patients, including diagnosis and comorbidities at pharmacies. Therefore, identifying inappropriate medications in certain diseases was not possible. Moreover, the precise evaluation of appropriateness of medications that required data about specific conditions (eg, renal function, indication, and duration of treatment) was not possible. The mentioned limitation also led to the unavailability of the outcomes of the PIM administrations. In the present study, all the prescriptions for geriatrics were included with no limitation regarding the prescribers, which resulted in the limited number of prescriptions written by certain specialists, including dermatologists and gynecologists that could not be compared with other specialists.

\section{Conclusion}

Interventions are needed to improve the prescribing habits of GPs for the elderly, especially with respect to prescribing PIMs. Also, some problems still exist in rational use of drugs as evaluated by the WHO prescribing indices, especially, the prescription of the brand-name medications and injectable medications.

\section{Acknowledgments}

This research has been supported by Tehran University of Medical Sciences \& health Services (Grant No. 92-02156-23585).

\section{Conflict of Interests}

The authors declare that they have no competing interests.

\section{References}

1. Lavan AH, Gallagher P. Predicting risk of adverse drug reactions in older adults. Ther Adv Drug Saf. 2016;7(1):11-22.

2. Ryan C, O’Mahony D, Kennedy J, Weedle P, Barry P, Gallagher P, et al. Appropriate prescribing in the elderly: an investigation of two screening tools, Beers Criteria considering diagnosis and independent of diagnosis and improved prescribing in the elderly tool to identify inappropriate use of medicines in the elderly in primary care in Ireland. J Clin Pharm Ther. 2009;34(4):369-76.

3. Guaraldo L, Cano FG, Damasceno GS, Rozenfeld S. Inappropriate medication use among the elderly: a systematic review of administrative databases. BMC Geriatr. 2011;11(1):79.

4. O'Mahony D, Gallagher PF. Inappropriate prescribing in the older population: need for new criteria. Age Ageing. 2008;37(2):138-41.

5. Motter FR, Fritzen JS, Hilmer SN, Paniz ÉV, Paniz VMV. Potentially inappropriate medication in the elderly: a systematic review of validated explicit criteria. Eur J Clin Pharmacol. 2018:1-22.

6. Hamilton HJ, Gallagher PF, O'Mahony D. Inappropriate prescribing and adverse drug events in older people. BMC Geriatr. 2009;9(1):1.

7. Bloom DE, Canning D, Fink G. Implications of population ageing for economic growth. Oxford Rev Econ Pol. 2010;26(4):583-612.

8. Tajvar M, Arab M, Montazeri A. Determinants of health-related quality of life in elderly in Tehran, Iran. BMC public health 2008;8(1): 1 .

9. Noroozian M. The elderly population in iran: an ever growing concern in the health system. Iran $\mathbf{J}$ Psychiatry Behav Sci. 2012;6(2):1-6.

10. Beers MH, Ouslander JG, Rollingher I, Reuben DB, Brooks J, Beck JC. Explicit criteria for determining inappropriate medication use in nursing home residents. Arch Intern Med. 1991;151(9):1825-32.

11. Fialová D, Topinková E, Gambassi G, Finne-Soveri H, Jónsson PV, Carpenter I, et al. Potentially inappropriate medication use among elderly home care patients in Europe. JAMA. 2005;293(11):1348-58.

12. Waller JL, Maclean JR. Updating the Beers Criteria for potentially inappropriate medication use in older adults. Arch Intern Med. 2003;163:2716-24

13. Campanelli CM. American Geriatrics Society updated Beers Criteria for potentially inappropriate medication use in older adults: the American Geriatrics Society 2012 Beers Criteria Update Expert Panel. J Am Geriatr Soc. 2012;60(4):616.

14. Desalegn AA. Assessment of drug use pattern using WHO prescribing indicators at Hawassa University teaching and referral hospital, south Ethiopia: a cross-sectional study. BMC Health Serv Res. 2013;13(1):1.

15. Anker M, Jokobowicz B, Fresle D, Hozerzil H. How to investigate drug use in health facilities. WHO/DAP. 1993.

16. Mosleh A, Khoshnevis Ansari S, Sorush M, Eghbalpor A, Babaeian $\mathrm{S}$. Evaluation of the drug prescription status based on the WHO indices in pharmacies of health care centers affiliated to Tehran University of Medical Sciences. MJIRI. 2011;25(4):222-5.

17. El Mahalli A. WHO/INRUD drug prescribing indicators at primary health care centres in Eastern province, Saudi Arabia. East Mediterr Health J.2012;18(11):1091.

18. Zarifyeganeh M, Kargar M, Rashidian A, Jafarzadeh Kohneloo A, Gholami Kh, Out of pocket payment and affordability of medication for geriatric patients in Tehran, Iran. Iran J Public Health. 2019 Jun (48); 6:1124-32

19. Atrianfar F, Rezaei F, Heidari K, Kargar M, Javadi MR, Gholami $\mathrm{Kh}$, Drug-drug interactions and potentially inappropriate medications among elderly outpatients, Braz J Pharm Sci. In press. 2020

20. Organization WH. WHO model list of essential medicines: 18th list, April 2013. 2013.

21. Ghadimi H, Esmaily HM, Wahlstrom R. General practitioners' prescribing patterns for the elderly in a province of Iran. Pharmacoepidemiol Drug Saf. 2011;20(5):482-7.

22. Vali L, Pourreza A, Foroushani AR, Sari AA, Honarmand H. An Investigation on Inappropriate Medication Applied among Elderly Patients. World Appl Sci J. 2012;16(6):819-25.

23. Azoulay L, Zargarzadeh A, Salahshouri Z, Oraichi D, Bérard A. Inappropriate medication prescribing in community-dwelling elderly people living in Iran. Eur J Clin Pharmacol.2005;61(12):913-9.

24. Zargarzadeh AH, Sadeghi K, Mirmoghtadaei P. Prescribing of Potentially Inappropriate Medications to Elderly People by Medical Specialists in Isfahan, Iran. IJPS. 2008;4(4):241-6.

25. Talebi-Taher M, Javad-Moosavi S, Taherian S, Barati M. Surveying the inappropriate drug adminstrution using Beers Criteria in elderly patients at the internal medicine ward of Rasoul-e-Akram Hospital of Tehran in 2012. Arak Medical University Journal. 2014;17(2):33-9.

26. Gallagher P, O'Mahony D. STOPP (Screening Tool of Older Persons' potentially inappropriate Prescriptions): application to acutely ill elderly patients and comparison with Beers' criteria. Age Ageing. 2008;37(6):673-9.

27. Akazawa M, Imai H, Igarashi A, Tsutani K. Potentially inappropriate medication use in elderly Japanese patients. Am J Geriatr Pharmacother. 2010;8(2):146-60.

28. Undela K, Bansal D, D'Cruz S, Sachdev A, Tiwari P. Prevalence and determinants of use of potentially inappropriate medications in elderly inpatients: a prospective study in a tertiary healthcare setting. Geriatr Gerontol Int. 2014;14(2):251-8.

29. de Oliveira Baldoni A, Ayres LR, Martinez EZ, Dewulf Nde L, Dos Santos V, Pereira LR. Factors associated with potentially inappropriate medications use by the elderly according to Beers Criteria 2003 and 2012. Int J Clin Pharm. 2014;36(2):316-24.

30. Fadare JO, Agboola SM, Opeke OA, Alabi RA. Prescription pattern and prevalence of potentially inappropriate medications among elderly patients in a Nigerian rural tertiary hospital. Ther Clin Risk Manag. 2013;6:115. 
31. Pradhan S, Panda A, Mohanty M, Behera J, Ramani Y, Pradhan P. A study of the prevalence of potentially inappropriate medication in elderly in a tertiary care teaching hospital in the state of Odisha. Int $\mathbf{J}$ Med Public Health. 2015;5(4).

32. Nishtala PS, Bagge ML, Campbell AJ, Tordoff JM. Potentially inappropriate medicines in a cohort of community-dwelling older people in New Zealand. Geriatr Gerontol Int. 2014;14(1):89-93.

33. Davidoff AJ, Miller GE, Sarpong EM, Yang E, Brandt N, Fick DM Prevalence of potentially inappropriate medication use in older adults using the 2012 Beers Criteria. J Am Geriatr Soc. 2015;63(3):486-500.

34. Soleymani F, Valadkhani M, Dinarvand R. Challenges and achievements of promoting rational use of drugs in Iran. Iran J Public Health. 2009;38(Supple1):166-8.

35. Karimi A, Haerizadeh M, Soleymani F, Haerizadeh M, Taheri F. Evaluation of medicine prescription pattern using World Health Organization prescribing indicators in Iran: A cross-sectional study. J Res Pharm Pract. 2014;3(2):39.

36. Sadeghian G-H, Safaeian L, Mahdanian AR, Salami S, KebriaeeZadeh J. Prescribing quality in medical specialists in isfahan, iran. Iran J Pharm Res. 2013;12(1):235-41.

37. Cheraghali A, Nikfar S, Behmanesh Y, Rahimi V, Habibipour F, Tirdad R, et al. Evaluation of availability, accessibility and prescribing pattern of medicines in the Islamic Republic of Iran. East Mediterr Health J. 2004.

38. Eze UI, Olowu AO. Prescribing patterns and inappropriate use of medications in elderly outpatients in a tertiary hospital in Nigeria. Trop J Pharm Res. 2011;10(1).

39. Zaveri H, Mansuri S, Patel V. Use of potentially inappropriate medicines in elderly: A prospective study in medicine out-patient department of a tertiary care teaching hospital. Indian J Pharmacol. 2010;42(2):95.

40. Craftman $\AA$ G, Johnell K, Fastbom J, Westerbotn M, von Strauss E. Time trends in 20 years of medication use in older adults: findings from three elderly cohorts in Stockholm, Sweden. Arch Gerontol Geriatr. 2016;63:28-35.

41. Safaeian L, Mahdanian A-R, Hashemi-Fesharaki M, Salami S, Kebriaee-Zadeh J, Sadeghian G-H. General physicians and prescribing pattern in Isfahan, Iran. Oman Med J. 2011;26(3):205-6.

42. Vooss AT, Diefenthaeler HS. Evaluation of prescription indicators established by the WHO in Getúlio Vargas-RS. Brazil J Pharm Sci. 2011;47(2):385-90. 
Supplementary Table 1. The modified list of the Beers criteria

\begin{tabular}{|c|c|c|}
\hline $\begin{array}{l}\text { Organ System or Therapeutic } \\
\text { Category or Drug to be Avoided }\end{array}$ & Beers Criteria Descriptions & Modifications \\
\hline \multicolumn{3}{|l|}{ Anticholinergics (excludes TCAs) } \\
\hline $\begin{array}{l}\text { First-generation antihistamines (as single agent or as } \\
\text { part of } \\
\text { combination products) } \\
\text { Brompheniramine } \\
\text { Carbinoxamine } \\
\text { Chlorpheniramine } \\
\text { Clemastine }\end{array}$ & $\begin{array}{l}\text { Use of diphenhydramine in special } \\
\text { situations such as acute treatment } \\
\text { of severe allergic reaction may be } \\
\text { appropriate }\end{array}$ & $\begin{array}{c}\text { Cold preparations containing "chlor- } \\
\text { pheniramine" (such as Biolenol cold }{ }^{\circledR} \text {, Adult } \\
\left.\text { cold, Cold gel }{ }^{\circledR}\right) \text {, Expectorant, Antihistamine } \\
\text { Decongestant and all other antihistamines } \\
\text { listed: GIM }\end{array}$ \\
\hline Cyproheptadine & & Dimenhydrinate, Diphenhydramine and Cold \\
\hline Dexbrompheniramine & & preparations containing Diphenhydramine \\
\hline Dexchlorpheniramine & & $\left(\right.$ such as Coldax $^{\circledR}$, Cold stop $^{\circledR}$ ): CIM \\
\hline \multicolumn{3}{|l|}{ Diphenhydramine (oral) } \\
\hline \multicolumn{3}{|l|}{ Doxylamine } \\
\hline \multicolumn{3}{|l|}{ Hydroxyzine } \\
\hline \multicolumn{3}{|l|}{ Promethazine } \\
\hline \multicolumn{3}{|l|}{ Triprolidine } \\
\hline Antiparkinson agents & - & GIM \\
\hline \multicolumn{3}{|l|}{ Benztropine (oral) } \\
\hline \multicolumn{3}{|l|}{ Trihexyphenidyl } \\
\hline Antispasmodics & Avoid except in & In prescriptions without chemotherapeutic \\
\hline Belladonna alkaloids & short-term palliative & agents as a marker for palliative care: GIM \\
\hline Clidinium-chlordiazepoxide & care to decrease & \\
\hline Dicyclomine & oral secretions & Clidinium-chlordiazepoxide: GIM \\
\hline \multicolumn{3}{|l|}{ Hyoscyamine } \\
\hline \multicolumn{3}{|l|}{ Propantheline } \\
\hline \multicolumn{3}{|l|}{ Scopolamine } \\
\hline \multicolumn{3}{|l|}{ Antithrombotics } \\
\hline $\begin{array}{l}\text { Dipyridamole, oral short acting } \\
\text { (does not apply to extended release combination } \\
\text { with aspirin) }\end{array}$ & - & GIM \\
\hline Ticlopidine & - & GIM \\
\hline \multicolumn{3}{|l|}{ Anti-infective } \\
\hline Nitrofurantoin & $\begin{array}{l}\text { Avoid for long-term } \\
\text { suppression; avoid in } \\
\text { patients with } \\
\mathrm{CrCl}<60 \mathrm{~mL} / \mathrm{min}\end{array}$ & $\begin{array}{l}\text { GIM: if prescribed for }>2 \text { weeks (prescrip- } \\
\text { tion with }>56 \text { tablets if daily dosing was not } \\
\text { mentioned in the prescription) } \\
\text { If the number of tablet was lower: CIM }\end{array}$ \\
\hline \multicolumn{3}{|l|}{ Cardiovascular } \\
\hline Alpha1 blockers & Avoid use as an & GIM: if prescribed for women, or prescribed \\
\hline Doxazosin & antihypertensive & for men along with other antihypertensive \\
\hline Prazosin & & medications \\
\hline Terazosin & & Otherwise: CIM \\
\hline Alpha agonists, central & Avoid clonidine as & GIM \\
\hline Clonidine & a first-line & \\
\hline Guanabenz & antihypertensive. & \\
\hline Guanfacine & Avoid others as listed & \\
\hline \multicolumn{3}{|l|}{ Methyldopa } \\
\hline \multicolumn{3}{|l|}{ Reserpine $(>0.1 \mathrm{mg} / \mathrm{d})$} \\
\hline $\begin{array}{l}\text { Antiarrhythmic drugs (Class Ia, Ic, } \\
\text { III) }\end{array}$ & $\begin{array}{l}\text { Avoid antiarrhythmic } \\
\text { drugs as first-line }\end{array}$ & CIM \\
\hline Amiodarone & treatment of atrial & \\
\hline Dofetilide & fibrillation & \\
\hline \multicolumn{3}{|l|}{ Dronedarone } \\
\hline \multicolumn{3}{|l|}{ Flecainide } \\
\hline \multicolumn{3}{|l|}{ Ibutilide } \\
\hline Procainamide & & \\
\hline Propafenone & & \\
\hline Quinidine & & \\
\hline Sotalol & & \\
\hline Disopyramide & - & GIM \\
\hline Dronedarone & $\begin{array}{l}\text { Avoid in patients with } \\
\text { permanent atrial } \\
\text { fibrillation or heart } \\
\text { failure }\end{array}$ & CIM \\
\hline Digoxin $>0.125 \mathrm{mg} / \mathrm{d}$ & - & $\begin{array}{c}\text { GIM: If the daily dose was mentioned in the } \\
\text { prescription and was }>0.125 \mathrm{mg} / \mathrm{d} \\
\text { Without daily does: CIM }\end{array}$ \\
\hline Nifedipine, immediate release & - & GIM \\
\hline
\end{tabular}




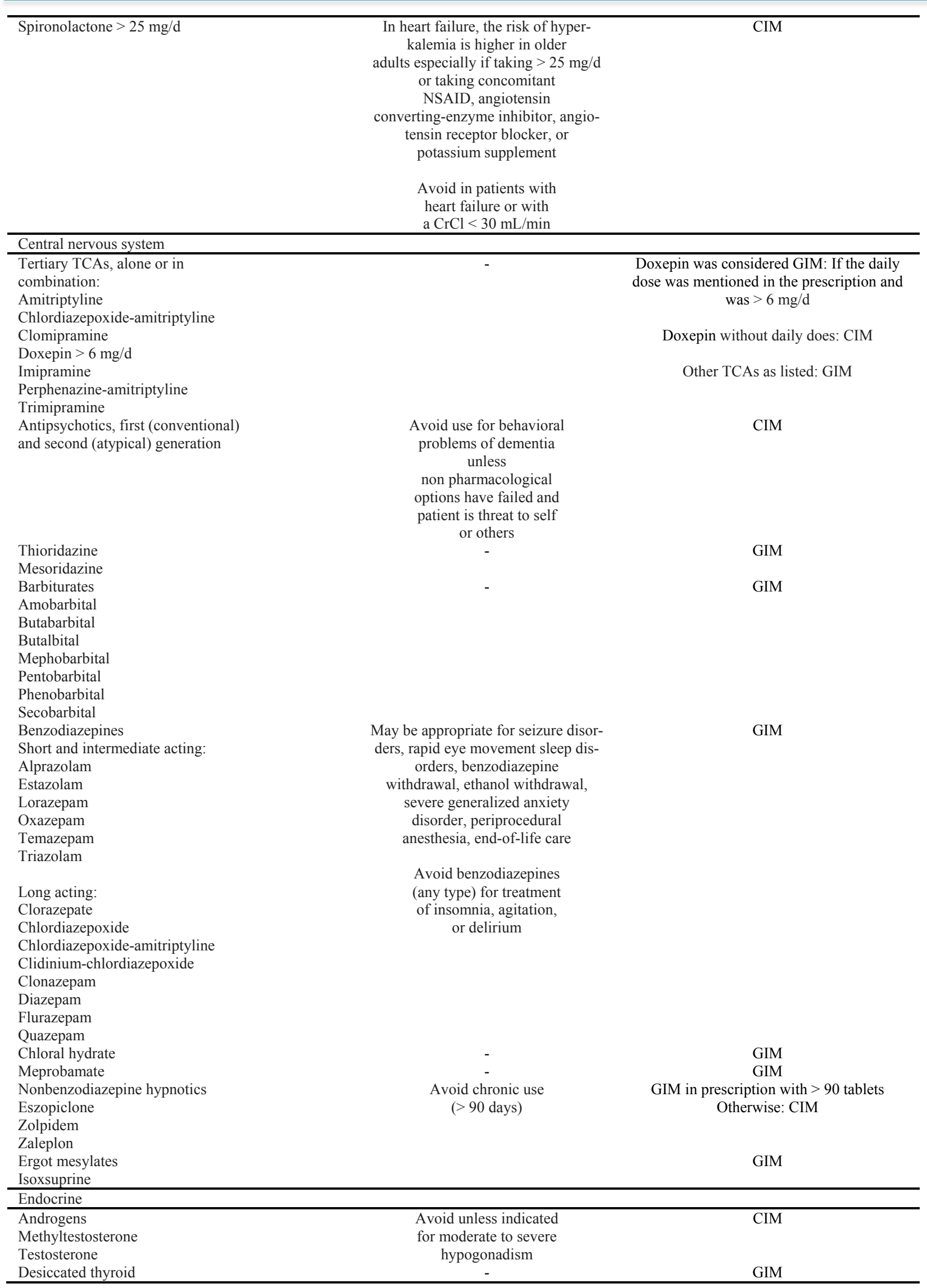




\begin{tabular}{|c|c|c|}
\hline $\begin{array}{l}\text { Estrogens with or without } \\
\text { progestins }\end{array}$ & $\begin{array}{c}\text { Evidence that vaginal estrogens for } \\
\text { treatment of vaginal dryness is safe } \\
\text { and effective in women with breast } \\
\text { cancer, especially at } \\
\text { dosages of estradiol }<25 \mathrm{lg} \text { twice } \\
\text { weekly } \\
\text { Avoid oral and topical } \\
\text { patch. } \\
\text { Topical vaginal cream: } \\
\text { acceptable to use } \\
\text { low-dose intravaginal } \\
\text { estrogen for the } \\
\text { management of } \\
\text { dyspareunia, lower } \\
\text { urinary tract infections, } \\
\text { and other vaginal } \\
\text { symptoms }\end{array}$ & $\begin{array}{c}\text { GIM: if administered as oral and topical } \\
\text { patch. } \\
\text { Otherwise : CIM }\end{array}$ \\
\hline Growth hormone & $\begin{array}{l}\text { Avoid, except as } \\
\text { hormone replacement } \\
\text { after pituitary gland } \\
\text { removal }\end{array}$ & CIM \\
\hline $\begin{array}{l}\text { Insulin, sliding scale } \\
\text { Megestrol } \\
\text { Sulfonylureas, long duration } \\
\text { Chlorpropamide } \\
\text { Glyburide }\end{array}$ & $\begin{array}{l}- \\
- \\
-\end{array}$ & $\begin{array}{l}\text { GIM } \\
\text { GIM } \\
\text { GIM }\end{array}$ \\
\hline Gastrointestinal & & \\
\hline Metoclopramide & $\begin{array}{l}\text { Avoid, unless for } \\
\text { gastroparesis }\end{array}$ & CIM \\
\hline $\begin{array}{l}\text { Mineral oil, oral } \\
\text { Trimethobenzamide }\end{array}$ & $\begin{array}{l}- \\
- \\
\end{array}$ & $\begin{array}{l}\text { GIM } \\
\text { GIM }\end{array}$ \\
\hline Pain & & \\
\hline $\begin{array}{l}\text { Meperidine } \\
\text { Non-COX-selective NSAIDs, oral } \\
\text { Aspirin }>325 \mathrm{mg} / \mathrm{d} \\
\text { Diclofenac } \\
\text { Diflunisal } \\
\text { Etodolac } \\
\text { Fenoprofen } \\
\text { Ibuprofen } \\
\text { Ketoprofen } \\
\text { Meclofenamate } \\
\text { Mefenamic acid } \\
\text { Meloxicam } \\
\text { Nabumetone } \\
\text { Naproxen } \\
\text { Oxaprozin } \\
\text { Piroxicam } \\
\text { Sulindac } \\
\text { Tolmetin }\end{array}$ & $\begin{array}{l}- \\
\text { Avoid chronic use } \\
\text { unless other alternatives } \\
\text { are not effective and } \\
\text { patient can take } \\
\text { gastroprotective agent } \\
\text { (proton pump inhibitor } \\
\text { or misoprostol) }\end{array}$ & $\begin{array}{l}\text { GIM } \\
\text { GIM: if prescribed for }>30 \text { days } \\
\text { In prescriptions in which daily dosing was } \\
\text { not mentioned, GIM was determined if the } \\
\text { number of tablet/capsules exceeded the max } \\
\text { acceptable daily dose for } 30 \text { days }\end{array}$ \\
\hline $\begin{array}{l}\text { Indomethacin } \\
\text { Ketorolac, includes parenteral }\end{array}$ & - & GIM \\
\hline $\begin{array}{l}\text { Pentazocine } \\
\text { Skeletal muscle relaxants } \\
\text { Carisoprodol } \\
\text { Chlorzoxazone } \\
\text { Cyclobenzaprine } \\
\text { Metaxalone } \\
\text { Methocarbamol } \\
\text { Orphenadrine }\end{array}$ & - & $\begin{array}{l}\text { GIM } \\
\text { GIM }\end{array}$ \\
\hline
\end{tabular}


Supplementary Table 2. The modified list of systemic and local antibiotic medications

\begin{tabular}{|c|c|}
\hline Systemic Antibiotics & Dosage Forms \\
\hline \multirow[t]{2}{*}{ Amoxicillin } & Capule:250 mg, $500 \mathrm{mg}$ \\
\hline & Powder, For Suspension: $125 \mathrm{mg} / 5 \mathrm{ml}, 250 \mathrm{mg} / 5 \mathrm{ml}$ \\
\hline \multirow[t]{2}{*}{ Amoxicillin +Clavulanic Acid } & Tablet: $375,625 \mathrm{mg}$ \\
\hline & $\begin{array}{l}\text { Powder, For Suspension: } 156(125+31.25) / 5 \mathrm{ml}, 228(200+28.2) / 5 \mathrm{ml}, 312(250+62.5) / 5 \mathrm{ml}, 457 \\
\qquad(400+57) / 5 \mathrm{ml}\end{array}$ \\
\hline \multirow[t]{3}{*}{ Ampicillin } & Capsule:250 mg, $500 \mathrm{mg}$ \\
\hline & Injection Powder: $500 \mathrm{mg}, 1 \mathrm{~g}$ \\
\hline & Powder, For Suspension: $125 \mathrm{mg} / 5 \mathrm{ml}, 250 \mathrm{mg} / 5 \mathrm{ml}$ \\
\hline Ampicillin+Sulbactam & Injection Powder: $1.5 \mathrm{~g}, 3 \mathrm{~g}$ \\
\hline Penicillin 6-3-3 & Injection Powder \\
\hline Penicillin G Benzathine & Injection Powder, Extended Release: $1200000 \mathrm{U}$ \\
\hline Panicillin G Procaine & Injection Powder: $400000 \mathrm{U}, 800000 \mathrm{U}$ \\
\hline \multirow{2}{*}{ Penicillin V } & Tablet:500mg \\
\hline & Powder, For Suspension: $125 \mathrm{mg} / 5 \mathrm{ml}, 250 \mathrm{mg} / 5 \mathrm{ml}$ \\
\hline \multirow[t]{2}{*}{ Cloxacillin } & Capsule: $250 \mathrm{mg}, 500 \mathrm{mg}$ \\
\hline & Injection Powder: $250 \mathrm{mg}, 500 \mathrm{mg}, 1 \mathrm{~g}$ \\
\hline Piperacillin+Tazobactam & Injection Powder: $1.125 \mathrm{~g}, 2.5 \mathrm{~g}, 3.375 \mathrm{~g}, 4.5 \mathrm{~g}$ \\
\hline \multirow[t]{2}{*}{ Cefalexin } & Capsule: $250 \mathrm{mg}, 500 \mathrm{mg}$ \\
\hline & $\begin{array}{l}\text { Powder, For Suspension: } 125 \mathrm{mg} / 5 \mathrm{ml}, 250 \mathrm{mg} / 5 \mathrm{ml} \\
\text { Injection Powder: } 500 \mathrm{mg}, 1 \mathrm{~g}\end{array}$ \\
\hline \multirow[t]{2}{*}{ Cefixime } & Capsule: $200 \mathrm{mg}, 400 \mathrm{mg}$ \\
\hline & Powder, For Suspension: $100 \mathrm{mg} / 5 \mathrm{ml}$ \\
\hline Ceftriaxone & Injection Powder: $500 \mathrm{mg}, 1 \mathrm{~g}$ \\
\hline \multirow[t]{3}{*}{ Cefuroxim } & Tablet: $125 \mathrm{mg}, 250 \mathrm{mg}, 500 \mathrm{mg}$ \\
\hline & Injection Powder: $750 \mathrm{mg}, 1.5 \mathrm{~g}$ \\
\hline & Powder, For Suspension: $125 \mathrm{mg} / 5 \mathrm{ml}$ \\
\hline Cefotaxime & Injection Powder: 500mg, $1 \mathrm{~g}$ \\
\hline Ceftazidime & Injection Powder: $500 \mathrm{mg}, 1 \mathrm{~g}, 2 \mathrm{~g}$ \\
\hline Ceftizoxim & Injection Powder: $500 \mathrm{mg}, 1 \mathrm{~g}$ \\
\hline Cefepim & Injection Powder: $500 \mathrm{mg}, 1 \mathrm{~g}, 2 \mathrm{G}$ \\
\hline Imipenem + Cilastatin & Injection Powder: $500 \mathrm{mg}$ \\
\hline Vancomycin & Injection Powder: 500mg \\
\hline \multirow[t]{3}{*}{ Clindamycin } & Capsule:150mg, 300mg \\
\hline & Injection: $300 \mathrm{mg} / 2 \mathrm{ml}$ \\
\hline & Suspension: 75 mg/5ml \\
\hline Meropenem & Injection Powder: $500 \mathrm{mg}, 1 \mathrm{~g}$ \\
\hline \multirow{2}{*}{ Azithromycin } & Capsule: $250 \mathrm{mg}, 500 \mathrm{mg}$ \\
\hline & Powder, For Suspension: $100 \mathrm{mg} / 5 \mathrm{ml}, 200 \mathrm{mg} / 5 \mathrm{ml}$ \\
\hline \multirow[t]{3}{*}{ Erythromycin } & Injection Powder: $1 \mathrm{~g}$ \\
\hline & Powder, For Suspension: $200 \mathrm{mg} / 5 \mathrm{ml}$ \\
\hline & Tablet: $200 \mathrm{mg}, 400 \mathrm{mg}$ \\
\hline Clarithromycin & Tablet: $250 \mathrm{mg}, 500 \mathrm{mg}$ \\
\hline \multirow[t]{2}{*}{ Chloramphenicol } & Capsule: $250 \mathrm{mg}$ \\
\hline & Injection Powder: $1 \mathrm{~g}$ \\
\hline \multirow[t]{2}{*}{ Ciprofloxacin } & Injection, Solution: $200 \mathrm{mg} / 100 \mathrm{ml}$ \\
\hline & Tablet: $250 \mathrm{mg}, 500 \mathrm{mg}$ \\
\hline \multirow[t]{2}{*}{ Nalidixic Acid } & Tablet: $500 \mathrm{mg}$ \\
\hline & Suspension: $300 \mathrm{mg} / 5 \mathrm{ml}$ \\
\hline Ofloxacin & Tablet:200 mg, 300mg \\
\hline Gemifloxacin & Tablet:320mg \\
\hline Levofloxacin & Tablet: $250 \mathrm{mg}, 500 \mathrm{mg}$ \\
\hline Moxifloxacin & Tablet:400 mg \\
\hline Tetracycline & Capsule:250mg \\
\hline & Injection: $500 \mathrm{mg} / 2 \mathrm{ml}$ \\
\hline Doxycycline & Capsule:100mg \\
\hline Gentamicin & Injection: $20 \mathrm{mg} / 2 \mathrm{ml}, 40 \mathrm{mg} / 1 \mathrm{ml}, 80 \mathrm{mg} / 2 \mathrm{ml}$ \\
\hline Amikacin & Injection: $100 \mathrm{mg} / 2 \mathrm{ml}, 500 \mathrm{mg} / 2 \mathrm{ml}$ \\
\hline Streptomycin & Injection Powder: $1 \mathrm{~g}$ \\
\hline Spectinomycin & Injection Powder: $2 \mathrm{~g}$ \\
\hline Tobramycin & Injection: 10 mg/ml,40mg/ml \\
\hline Metronidazole & Injection Solution: $500 \mathrm{mg} / 100 \mathrm{ml}$ \\
\hline & Tablet:250 mg \\
\hline & Suspension: $125 \mathrm{mg} / 5 \mathrm{ml}$ \\
\hline Nitrofurantoin & Suspension: $25 \mathrm{mg} / 5 \mathrm{ml}, 12.5 \mathrm{mg} / 5 \mathrm{ml}$ \\
\hline & Tablet: $100 \mathrm{mg}$ \\
\hline Sulfamethoxazole +Trimethoprim & Injection Solution:400+80mg $/ 5 \mathrm{ml}$ \\
\hline & Tablet: $100+20 \mathrm{mg} ; 400+80 \mathrm{mg}, 800+160 \mathrm{mg}$ \\
\hline & Suspension: $200+40 \mathrm{mg} / 5 \mathrm{ml}$ \\
\hline Trimethoprim & Oral Liquid: $50 \mathrm{mg} / 5 \mathrm{ml}$ \\
\hline & Tablet: $100 \mathrm{mg} ; 200 \mathrm{mg}$. \\
\hline
\end{tabular}




\begin{tabular}{lc}
\hline Local Antibiotics & Dosage forms \\
\hline Mupirocin & Ointment: $2 \%$ \\
Potassium Permanganate & Aqueous solution: $1: 10000$ \\
Silver Sulfadiazine & Cream: $1 \%$ \\
Acyclovir & Ointment: $3 \%$ \\
Gentamicin & Eye Drops: $0.3 \%$ \\
Tetracycline & Eye Ointment: $1 \%$ \\
Ofloxacin & Eye Drop: $0.3 \%$ \\
Ciprofloxacin & Eye Ointment: $0.3 \%$ \\
Erythromycin & Eye Ointment: $0.5 \%$ \\
\hline Some of the medications or dosage form that was listed in the WHO model list was not available in Iran at the study time. However, we did not remove & \\
them from the table. &
\end{tabular}

